\title{
Sensitivity study of the influence of changes in canopy characteristics on evaporation loss and soil moisture using a sparse vegetation model
}

\author{
J. G. Lockwood \\ School of Geography, University of Leeds, Leeds LS2 9JT, United Kingdom
}

\begin{abstract}
A sparse vegetation model based on further development of the work of Shuttleworth \& Wallace (1985; Q. J. R. Meteorol. Soc. 111: 839-855) is used to estimate evaporative loss and soil moisture over 3 yr for a seasonally growing bracken canopy (Pteridium aquilinum) at a site in northern England. It is found that soil surface evaporation from moist soils is an important component of the total evaporative loss in very sparse canopies [LAI (leaf area index) below 0.5 ]. With LAI values below ca 0.5 , and moist soils, canopy stomatal controls are not strongly influencing total evaporative loss. In contrast, there is a tendency for 10-day average transpiration loss to become constant with increasing LAI for LAI values above ca 2 . The model is also used for sensitivity studies on the influence of small changes in bracken canopy characteristics (bulk canopy resistance. LAI and height) on evaporative loss and soi] moisture. It is found that the percentage change in transpiration loss is always less than the percentage change in canopy characteristics. This is particularly so in the case of bulk canopy resistance. The reasons for this are explored. It is found that year-to-year variations in weather inputs are likely to swamp small changes in canopy characteristics due to either long-term climatic changes or errors in field parameterizations.
\end{abstract}

\section{(1) INTRODUCTION}

This paper describes the results of a numerical experiment in which the responses of evaporative loss and soil moisture balance to variations in the characteristics of a growing sparse bracken canopy (Pteridium aquilinum) were investigated. This experiment yielded information on the sensitivity of transpiration, interception loss and soil surface evaporation to small changes in bulk canopy resistance, leaf area index (LAI) and vegetation height. The experiment had 2 main components. Firstly, it described for a 3 yr period the changes in transpiration, interception loss and soil surface evaporation that occur as a bracken covered area changes from a bare surface to a closed canopy. Secondly, it investigated, using sensitivity studies, the influence of small changes in the characteristics of the growing canopy on the evaporative partitioning. The standard unilayer Penman-Monteith equation does not directly yield information on transpiration and soil surface evaporation as separate entities.
Since soil surface evaporation can dominate the total evaporative loss from very sparse vegetation covers after rainfall, it is essential that transpiration, soil surface evaporation and interception loss values are available separately. Therefore transpiration, soil surface and interception evaporative losses were estimated using a modified version of the Shuttleworth \& Wallace (1985) evaporative model for sparse vegetative covers. This is a one-dimensional model that provides a physically plausible description of the atmospheric turbulent fluxes during the transition between a bare substrate and a closed vegetation canopy. The equations are expressed in terms of conceptual resistances, using Ohm's law in electricity as a direct analogue, now familiar to micro-meteorologists and plant physiologists. The elements of which the model is composed (e.g. LAI, energy fluxes, etc.) are defined as horizontal averages over scales in which persistent features occur in sufficient numbers to allow averaging. Clearly a one-dimensional description is not relevant to horizontal scales more limited than this. In this paper the 
Shuttleworth \& Wallace (1985) model is used in a still novel manner to describe the variation in energy partitioning as a specific vegetation canopy grows. Atmospheric stability influences interception loss from wet vegetation canopies. Therefore rainfall interception loss and throughfall are also estimated by a combination of the Rutter unilayer model (Rutter et al. 1971) and the Penman-Monteith equation with the inclusion of an iterative technique to calculate an energy balance allowing for the effects of atmospheric stability on aerodynamic resistance.

After a brief description of the field site in Section 2, the modified version of the Shuttleworth \& Wallace (1985) model used to estimate evaporation from sparse vegetation covers is outlined in Section 3. Typical results from the model for the growing bracken canopy are then presented in Section 4, where the importance of soil surface evaporation as a component of the total evaporative loss in very sparse canopies (LAI below 0.5 ) is demonstrated, as well as the tendency for 10-day average transpiration to become constant with increasing LAI for LAI values above ca 2. The influence of small changes in the characteristics of the growing canopy on the evaporative partitioning between canopy and soil surface is explored by a series of sensitivity experiments varying bulk canopy resistance, LAI and canopy height. The results of these sensitivity studies, which are described at the end of the paper, are discussed in terms of canopy-atmosphere interactions. Canopy-atmosphere interactions are explored in Section 5, particularly with regard to the diabatic and adiabatic components of the evaporative loss. This study is a contribution towards understanding how vegetation stomatal control becomes more important than soil conditions in surface-atmosphere interactions as vegetation cover increases.

Any study of the sensitivity of evaporative loss to changes in observed canopy characteristics, such as those reported towards the end of this paper, must take into account that such changes may alter the observed canopy albedo and temperature and therefore the energy available for evaporation, and also the structure of the atmospheric mixed boundary layer and in particular its humidity deficit. Allowance can be made for this by placing a simple numerical model of the atmospheric mixed boundary layer above the model canopy and recomputing in response to canopy changes the available energy at the canopy surface and the meteorological conditions just above (e.g. Lockwood 1990 , 1992). This was not possible with the version of the Shuttleworth \& Wallace (1985) model used here, since it does not contain descriptions of canopy temperature or atmospheric stability. Instead, the approach used in this paper is to make only very small changes in the canopy structure so that the observed meteorological conditions directly above are not significantly changed. Since observations are available for a rapidly growing canopy the sensitivity study is carried out over a range of LAI values from nearly zero to about 4 and heights from about zero to $1 \mathrm{~m}$.

\section{(2) FIELD SITE AND FIELD MEASUREMENTS}

The field site used to collect data for the numerical experiment is described in Lockwood et al. (1989). It was located on a level open plateau at an altitude of around $250 \mathrm{~m}$ near Pateley Bridge, North Yorkshire, England. Observations were available for most of the summers of 1984, 1985 and 1986. Meteorological instrumentation consisted of a Didcot-type automatic weather station (Strangeways \& Smith 1985) providing hourly values of solar and net radiation, air temperature, wet bulb temperature, wind speed and rainfall, while soil moisture was measured weekly at $10 \mathrm{~cm}$ depth intervals at a variety of nearby sites using a Wallingford $\mathrm{Mk} 2$ neutron probe (Institute of Hydrology 1981j. To the standard automatic weather station were added a downward-facing solarimeter to measure reflected shortwave radiation and a soil heat flux plate just below the surface litter layer at $5 \mathrm{~cm}$ depth. The meteorological observations were made over an extensive area of bracken fern Pteridium aquilinum and weekly measurements of the LAI of randomly harvested bracken were made using an integrating TV camera. Bracken is dormant in the winter and the site is covered by bare litter only up to about Day 150 of the year. As shown in the summary bracken growth parameters in Table 1, bracken commenced growth at about Day 150, reaching full growth at about Day 200 with an LAI of around 4 and a height of just below $1 \mathrm{~m}$. Further details of bracken canopy and soil surface resistances are contained in Table 2, together with evaporation and rainfall data in Table 3. Both these tables are discussed in Section 4.

\section{(3) NUMERICAL MODEL}

Transpiration and soil surface evaporation were estimated using a version of the model for predicting evaporative loss from sparse vegetation covers described by Shuttleworth \& Wallace (1985). The original Shuttleworth \& Wallace model was modified to include a simple description of bracken stomatal conductance which varied with solar radiation, atmospheric water vapour deficit and soil moisture as described below. Bulk canopy resistance was calculated every hour by dividing the inverse of the stomatal conductance by the LAI. For any given LAI the bracken canopy has a 
Table 1. Seasonal course of selected vegetation parameters for a bracken fern canopy in 1984,1985 and 1986 . Height is in cm. LAI: leaf area index; SMD: estimated soil moisture deficit (mm); $r_{\mathrm{a}}$ : aerodynamic resistance (s $\mathrm{m}^{-1}$ ); $r_{\mathrm{s}}$ : bulk canopy resistance $\left(s \mathrm{~m}^{-1}\right)$. LAI and bracken height are averages for all 3 years, since the growth pattern does not vary greatly between years. Both $r_{d}$ and $r_{s}$ are averages over the period between 09:00 and 18:00 h GMT, centered roughly on the midday transpiration minimum

\begin{tabular}{|c|c|c|c|c|c|c|c|c|c|c|c|}
\hline \multirow[t]{2}{*}{ Day } & \multirow[t]{2}{*}{ LAI } & \multirow[t]{2}{*}{ Height } & \multicolumn{3}{|c|}{1984} & \multicolumn{3}{|c|}{1985} & \multicolumn{3}{|c|}{1986} \\
\hline & & & SMD & $I_{\mathrm{s}}$ & $r_{a}$ & SMD & $r_{s}$ & $r_{a}$ & SMD & $\Gamma_{\mathrm{s}}$ & $r_{\mathrm{a}}$ \\
\hline 150 & 0.0 & 0 & 1 & - & - & 3 & - & - & 2 & - & - \\
\hline 160 & 0.8 & 21 & 3 & 342 & 23 & 2 & 349 & 14 & 0 & 333 & 12 \\
\hline 170 & 1.5 & 37 & 9 & 237 & 27 & 9 & 203 & 52 & 12 & 189 & 14 \\
\hline 180 & 2.2 & 53 & 21 & 136 & 31 & 12 & 151 & 15 & 22 & 186 & 16 \\
\hline 190 & 2.9 & 69 & 48 & 218 & 23 & 32 & 121 & 14 & 43 & 114 & 17 \\
\hline 200 & 3.6 & 85 & 73 & 92 & 29 & 33 & 77 & 11 & 66 & 77 & 12 \\
\hline 210 & 4.0 & 94 & 93 & 75 & 9 & 0 & 61 & 17 & 71 & 63 & 8 \\
\hline
\end{tabular}

minimum bulk canopy resistance which is increased by variations in the environmental inputs just mentioned. The original Shuttleworth \& Wallace model was also modified to include a variable soil surface resistance dependent on soil moisture content which was computed hourly and a simple description of interception loss.

The method of calculating stomatal conductance, which is an addition to the original Shuttleworth \& Wallace model, is based on the work of Roberts et al. (1984) for woodland bracken. The stomatal conductance, $G_{s}\left(\mathrm{~mm} \mathrm{~s}^{-1}\right)$, is found by

$$
G_{s}=\mathrm{F} 1 \times \mathrm{F} 2 \times \mathrm{F} 3
$$

where $F 1=(4.58 Q) /(9.18+Q) ; Q=$ solar radiation $(W$ $\left.\mathrm{m}^{-2}\right) ; \mathrm{F} 2=1-0.059 D ; D=$ atmospheric specific humidity deficit $\left(\mathrm{g} \mathrm{kg}^{-1}\right) ; \mathrm{F} 3=1-\exp [-135.5(\theta-0.022)] ; \theta=$ average moisture volume fraction in soil, given by [(field capacity - soil moisture deficit)/soil depth]. Stomatal conductance is not particularly sensitive to changes in solar radiation $>100 \mathrm{~W} \mathrm{~m}^{-2}$, or soil moisture contents above ca $20 \%$ of field capacity. The maximum soil moisture deficit under bracken was set at $110 \mathrm{~mm}$.

A soil surface resistance is calculated which is analogous to a bulk canopy resistance for vegetation. The method of calculating soil resistance used in this paper is a modification to the original Shuttleworth \& Wallace model. This resistance is estimated hourly using a simple 2-layer parameterization of the hydrology of the surface litter/soil system based on Thompson et al. (1981). If the first layer (capacity $5 \mathrm{~mm}$ ) contains moisture, i.e. the litter is wet, the surface resistance is assumed to be $100 \mathrm{~s} \mathrm{~m}^{-1}$. When the first layer is dry, the surface resistance, $R_{\mathrm{sS}}\left(\mathrm{s} \mathrm{m}^{-1}\right)$, is calculated from

$$
R_{5 \mathrm{~s}}=100\left\{3.5\left(1-y / y_{\max }\right)+\exp \left[0.2\left(y_{\max } / y-1\right)\right]\right\}
$$

where $y$ is the current content of the second layer and $y_{\max }$ is the maximum capacity $(15 \mathrm{~mm})$ of the second layer. Rainfall during each hour recharges the first layer and when this layer reaches capacity, water is transferred to the second layer. This scheme produced soil surface resistances in the range 100 (wet/moist soil) to $2000 \mathrm{~s} \mathrm{~m}^{-1}$ (fairly dry soil). The second value corresponds to molecular diffusion through a $1.5 \mathrm{~cm}$ thick layer of dry sandy soil.

The method of estimating total evaporation from soil plus plants, $\lambda E$, follows Shuttleworth \& Wallace (1985):

$$
\lambda E=C_{c} \mathrm{PM}_{\mathrm{c}}+C_{\mathrm{s}} \mathrm{PM}_{\mathrm{s}}
$$

where $\mathrm{PM}_{c}$ and $\mathrm{PM}_{\mathrm{s}}$ are terms each similar to the Penman-Monteith combination equations which would apply to evaporation from a closed canopy and bare soil respectively and $\lambda$ is the latent heat of vaporization of water. The coefficients $C_{c}$ and $C_{s}$ depend upon the aerodynamic resistances associated with the soil, air within the canopy and air above the canopy, and the bulk canopy and soil surface resistances. Since the equations are too complex to reproduce here, the original Shuttleworth \& Wallace (1985) paper should be consulted for full details.

The aerodynamic resistances are calculated from crop height, wind speed and LAI. Shuttleworth \& Wallace (1985) assume the simplest possible model in which the within- and above-canopy resistances vary linearly with LAI between the values associated with their 2 limits, namely bare substrate and a complete canopy cover (LAI $=4$ ). In crops with complete cover the effective source, at which mean canopy air stream conditions are assumed to apply, is defined to occur at a height $\left(d+z_{0}\right)$ in the crop, where $d$ is zero plane displacement and $z_{0}$ is crop roughness length. Following Monteith \& Unsworth (1990) these were related to crop height, $h$, through $d=0.63 h$ and $z_{0}=0.13 h$. In sparser crops it is assumed that the effective source height remains fixed at this fraction of crop height. Measurements over the bare litter substrate gave the substrate roughness length as $0.005 \mathrm{~m}$.

The net radiation during daylight hours is primarily determined by the direct solar radiation, and the net 
radiation reaching the soil surface, $R_{\mathrm{n}}^{\mathrm{s}}$, is calculated using a Beer's law relationship of the form

$$
R_{\mathrm{n}}^{\mathrm{s}}=R_{\mathrm{n}} \exp (-C L)
$$

where $R_{n}$ is the net radiation above the canopy, $C$ is the extinction coefficient of the crop for net radiation, chosen arbitrarily as 0.7 , and $L$ is the LAI. The heat conduction into the substrate, $G$, is also arbitrarily set to $20 \%$ of the net radiation received at the substrate surface, $R_{\mathrm{n}}^{\mathrm{s}}$, and therefore $G$ also changes with crop density. Substrate surface available energy is defined as $R_{\mathrm{n}}^{\mathrm{s}}-G$.

Interception loss from the bracken canopy was described by an addition to the original Shuttleworth \& Wallace model using a Rutter-type drainage/evaporation expression with the assumption that drainage occurs when the rainfall storage on the vegetation exceeds $\sim 0.2 \mathrm{~mm}$ per LAI (Rutter et al. 1971, Pitman 1989). Rainfall interception by the vegetation canopy follows the basic description used by Thompson et al. (1981), and is a non-linear function of LAI. Since in this case atmospheric stability may have an important influence on the evaporative loss from wet surfaces, a version of the Penman-Monteith equation with the inclusion of an iterative technique to calculate an energy balance allowing for the effects of atmospheric stability on aerodynamic resistance was also used to estimate interception loss. This model is also described in Lockwood et al. (1989).

The input data required for the numerical models are hourly averages of solar and net radiation, air temperature, wet bulb temperature, wind speed and hourly totals of rainfall, all preferably from an automatic weather station. LAI and vegetation height are provided daily by a demographic growth scheme included within the models. Output consists of components of the evaporative loss, surface resistances, aerodynamic resistances within and above the canopy and soil moisture deficits. The models were integrated using hourly time steps except when the canopy was wet, when the time-step for estimating interception loss was 1 min.

Examples of the use of the Shuttleworth \& Wallace (1985) type of model may be found in Lockwood et al. (1989), Carlson et al. (1990), Kustas (1990), Lafleur \& Rouse (1990), and Wallace et al. (1990).

\section{(4) TYPICAL RESULTS FOR THE STANDARD MODEL}

Evaporative partitioning between canopy and soil changes as the bracken canopy develops. The model of energy exchanges in sparse canopies was applied to the 3 bracken growing seasons from 1984 to 1986, and the results are reported in this section. The conse- quences of evaporative partitioning between soil surface and canopy on soil moisture are also described.

Wallace et al. (1990), in their work on a crop of sparse dryland millet grown at the ICRISAT Sahelian Center, Niger, found in comparison to the Shuttleworth \& Wallace model that the Penman-Monteith equation underestimated transpiration when the soil was dry and overestimated it when the soil was wet. Comparisons with the transpiration plus soil evaporation rates estimated by the Penman-Monteith model used in this paper to estimate bracken interception loss and the version of the Shuttleworth \& Wallace model used here produced a similar result. Since the soil surface dries markedly as bracken growth commences, this

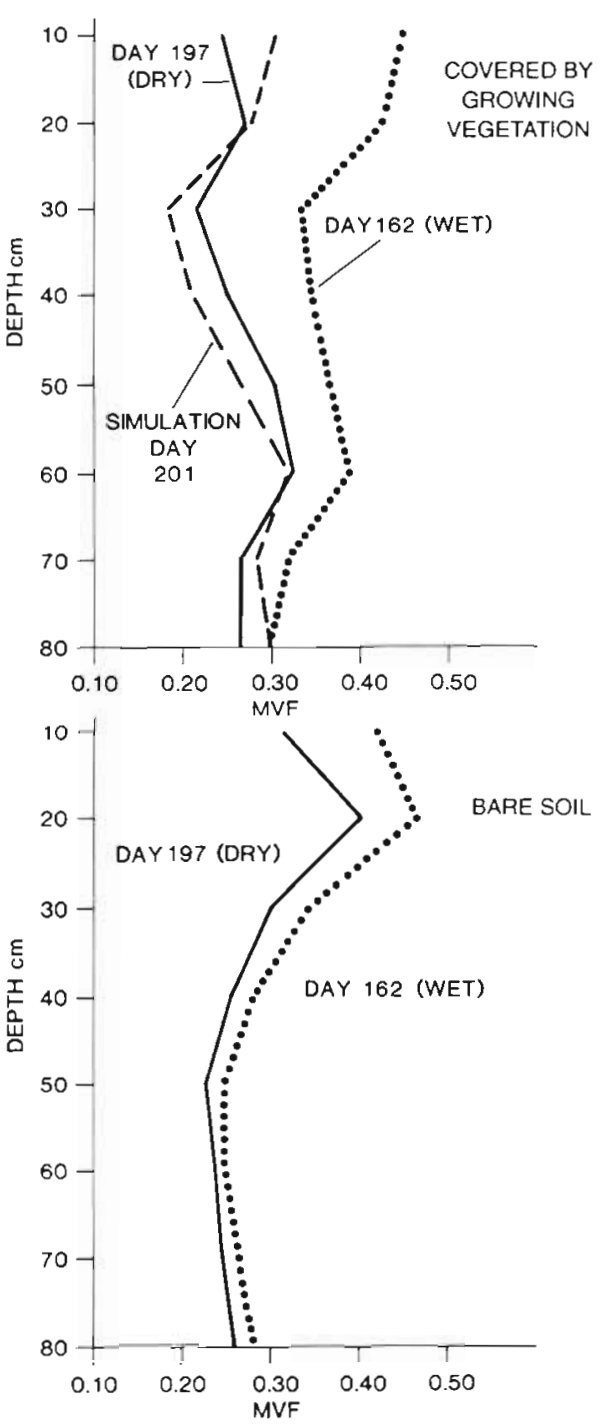

Fig. 1 Moisture volume fractions with depth at 2 sites on a horizontal surface with the same soil type at the Pateley Bridge field site during summer 1986 as measured by neutron moderation. Curves in top graph refer to an actively growing bracken stand, those in bottom graph to bare soil 
Table 2. Number of hours per 10-day period with bulk surface resistances within set limits, 1984

\begin{tabular}{|c|c|c|c|c|c|c|c|c|}
\hline \multirow[t]{2}{*}{ Days } & \multicolumn{8}{|c|}{ Bulk surface resistances ( $\mathrm{s} \mathrm{m}^{-1}$ ) } \\
\hline & $<100$ & $101-199$ & $200-299$ & $300-399$ & $400-499$ & $500-999$ & $1000-2999$ & $>3000$ \\
\hline \multicolumn{9}{|c|}{ Bracken canopy } \\
\hline $150-159$ & - & - & - & 24 & 20 & 71 & 55 & 70 \\
\hline $160-169$ & - & 4 & 111 & 49 & 4 & 10 & 2 & 60 \\
\hline $170-179$ & - & 116 & 51 & 8 & 5 & - & - & 60 \\
\hline $180-189$ & 2 & 153 & 18 & 3 & 2 & 1 & - & 61 \\
\hline $190-199$ & 104 & 53 & 10 & 8 & - & 3 & - & 62 \\
\hline $200-209$ & 99 & 62 & 2 & 4 & 2 & 1 & - & 70 \\
\hline \multicolumn{9}{|c|}{ Soil suríace } \\
\hline $150-159$ & 240 & - & - & - & - & - & - & - \\
\hline $160-169$ & 185 & 55 & - & - & - & - & - & - \\
\hline $170-179$ & 103 & 23 & 31 & 42 & 8 & 20 & 13 & - \\
\hline $180-189$ & 10 & - & - & - & - & - & 230 & - \\
\hline $190-199$ & 26 & - & - & - & - & - & 214 & - \\
\hline $200-209$ & 19 & - & - & - & - & - & 221 & - \\
\hline
\end{tabular}

property of the Penman-Monteith model significantly obscures the changes that take place in both transpiration and soil surface evaporation rates as the bracken grows. In particular it obscures the surge in evapotranspiration that occurs as bracken growth commences and the tendency for transpiration loss to become constant when LAI exceeds about 2.

Vegetation transpiration and soil surface evaporation act on soil moisture in different ways, and this is illustrated in Fig. 1. Fig. 1 shows moisture volume fractions with depth on a horizontal surface with the same soil type at the Pateley Bridge field site during summer 1986 as measured by neutron moderation. The curves in the top graph refer to an actively growing bracken stand, while the area around a second site $20 \mathrm{~m}$ away was sprayed with a soil-acting herbicide in April 1986 before bracken growth commenced. The initial curves refer to near-saturated soil at the start of bracken growth and the final ones to dry conditions at the time of maximum growth. Between the start and finish dates the base soil showed significant moisture loss in the first 20 to $30 \mathrm{~cm}$ depth, but below this depth the change in soil moisture was small. Across the same period, the similar soil with actively growing bracken showed significant moisture loss down to $80 \mathrm{~cm}$, which is about the limit of bracken roots at this site. Vegetation transpiration is therefore important in reducing soil moisture at depth and variations in transpiration are most likely to influence soil moisture below about $20 \mathrm{~cm}$ and not in the immediate surface layer.

Typical results produced by the model surface resistance schemes for 1984 are illustrated in Table 2. The number of hours in each 10 -day period with surface resistances within specified limits are shown for both the bracken canopy and the soil surface. During dark- ness at night (normally about 6 to $7 \mathrm{~h}$ at this latitude in summer) the canopy resistance is extremely high because of lack of light and is set at $3000 \mathrm{~s} \mathrm{~m}^{-1}$. Therefore in any 10-day period in Table 3 transpiration from the bracken will be effectively zero for between 20 and $30 \%$ of the time due to lack of light. As the LAI of bracken increases (Table 3), the frequency distribution of canopy resistances tends towards lower values. After Day 180 the number of hours with bulk canopy resistances below $200 \mathrm{~s} \mathrm{~m}^{-1}$ each 10-day period effectively becomes constant with values of 155, 157 and 161 , and this is reflected in the corresponding estimated transpiration totals of $25.56,26.16$ and $26.87 \mathrm{~mm}$ noted in Table 3.

At the start of the investigation period shown in Table 2 the surface litter layer is always wet and therefore surface resistances are always set at $100 \mathrm{~s}$ $\mathrm{m}^{-1}$. As the bracken fern grows the surface litter layer dries with a corresponding marked increase in the surface resistances. During the last two 10-day periods the bracken litter is very dry with high surface resistances for the majority of the time, but it is occasionally wetted by showers of rain. During the rain periods the surface litter becomes wet and the resistance decreases rapidly to $100 \mathrm{~s} \mathrm{~m}^{-1}$. Because only the surface layer is wet, whereas the soil at depth is extremely dry, the surface dries rapidly with a corresponding very rapid increase in the surface resistances. The result is a distribution in which the surface resistances of the bracken litter are usually very high (the surface is dry), but a few are very low (the surface is wet), with no values between them. Neither solar radiation nor vapour pressure deficit influences soil/itter surface resistances directly, and therefore the resistances show no consistent diurnal trends, unlike those for the bracken canopy. 
Table 3. Evapotransporation components, rainfall and average LAI of bracken fern for each 10-day period

\begin{tabular}{|c|c|c|c|c|c|}
\hline Days & $\begin{array}{l}\text { Transpiration } \\
\text { (mm) }\end{array}$ & $\begin{array}{l}\text { Soil evaporation } \\
\qquad(\mathrm{mm})\end{array}$ & $\begin{array}{l}\text { Interception Ioss } \\
\qquad(\mathrm{mm})\end{array}$ & $\begin{array}{l}\text { Rainfall } \\
\text { (mm) }\end{array}$ & Mean LAI \\
\hline \multicolumn{6}{|l|}{1984} \\
\hline $150-159$ & 3.33 & 2.07 & 0.82 & 22.5 & 0.38 \\
\hline $160-169$ & 11.96 & 0.86 & 1.50 & 13.5 & 1.08 \\
\hline $170-179$ & 19.02 & 1.47 & 1.52 & 11.0 & 1.77 \\
\hline $180-189$ & 25.56 & 0.43 & 0.41 & 0.5 & 2.47 \\
\hline $190-199$ & 26.16 & 0.58 & 1.40 & 3.0 & 3.16 \\
\hline $200-209$ & 26.87 & 0.31 & 1.85 & 9.5 & 3.86 \\
\hline Total & 112.90 & 5.72 & 7.50 & 60.0 & \\
\hline \multicolumn{6}{|l|}{1985} \\
\hline $150-159$ & 3.84 & 1.39 & 0.63 & 18.5 & 0.38 \\
\hline $160-169$ & 9.52 & 1.48 & 1.49 & 12.5 & 1.08 \\
\hline $170-179$ & 13.42 & 0.03 & 2.28 & 23.5 & 1.77 \\
\hline $180-189$ & 22.26 & 0.67 & 1.56 & 5.5 & 2.47 \\
\hline $190-199$ & 17.18 & 0.86 & 4.25 & 18.0 & 3.16 \\
\hline $200-209$ & 17.98 & 1.09 & 4.46 & 86.0 & 3.86 \\
\hline Total & 84.20 & 6.42 & 14.67 & 164.0 & \\
\hline \multicolumn{6}{|l|}{1986} \\
\hline $150-159$ & 3.91 & 4.46 & 0.50 & 7.5 & 0.38 \\
\hline $160-169$ & 10.79 & 1.20 & 1.59 & 30.5 & 1.08 \\
\hline $170-179$ & 14.41 & 0.71 & 1.42 & 8.0 & 1.77 \\
\hline $180-189$ & 21.86 & 0.46 & 1.48 & 2.5 & 2.47 \\
\hline $190-199$ & 23.17 & 0.53 & 0.00 & 0.0 & 3.16 \\
\hline $200-209$ & 21.23 & 0.68 & 5.55 & 23.5 & 3.86 \\
\hline Total & 95.37 & 8.04 & 10.54 & 72.0 & \\
\hline
\end{tabular}

Estimates of 10-day totals of transpiration, soil surface evaporation and interception loss (corrected for atmospheric stability) for bracken fern for the years 1984, 1985 and 1986 are shown in Table 3 together with the average LAI. In all 3 years the soil surface evaporation is a significant part of the total evaporative loss during the first 10-day period when the LAI is below 0.5 . Even with the LAI between about 0.5 and 2.0 the soil surface evaporation is estimated to be about $10 \%$ of the total evaporative loss. With LAI values below about 0.5 the interception loss is small and considerably less than the soil surface evaporation, and only when LAI exceeds about 3 does it significantly exceed the soil surface evaporation. Transpiration values increase with LAI until LAI values reach about 2, when they tend to remain nearly constant (1984 and 1986) or decrease slightly (1985).

Monteith (1986) comments that plants grow in 2 media - soil and air - and survive by coordinating the operation of roots and shoots. The argument is as follows. The supply of water provided by the root system of a crop stand may be defined in terms of the rate at which water is extracted by a root front moving downwards with a constant velocity, the available water per unit soil volume, and a time constant that is inversely proportional to root density. As a seedling grows within a stand of seedlings, its rate of transpiration must increase, and so also must the rate of root extension, to maintain a maximum transpiration rate. Eventually a point must be reached where the root front achieves a maximum downward velocity, the canopy is intercepting the maximum possible amount of solar radiation, and if there is no further input of water by rain or by irrigation, further growth of the plant and transpiration will be limited by available soil moisture. This is basically what is being observed in the bracken stand after LAI reaches 2 .

The importance of vegetation root structure in determining soil moisture profiles under drying conditions is illustrated in Fig. 1. This is a different problem from simulating runoff from wet soils since this is largely a property of soil structure and rainfall input. Five-day soil moisture profiles were simulated for bracken from Day 161 assuming a uniform root extension rate from the rhizomes at $30 \mathrm{~cm}$ depth and also assuming that the roots extracted moisture from the total depth of the soil above the advancing root front. The soil moisture extracted by the roots was taken as equal to the vegetation transpiration calculated by the Shuttleworth \& Wallace (1985) model. Soil surface evaporation was not considered to influence soil moisture profiles below about $20 \mathrm{~cm}$. The neutron moderation profile on Day 197 is also shown in Fig. 1, and the fit between the simulated and observed moisture volume fractions is reasonable. 


\section{(5) CANOPY-ATMOSPHERE INTERACTIONS}

McNaughton \& Jarvis (1983) re-wrote the PenmanMonteith equation in the form:

$$
\lambda E=\Omega \lambda E_{Q}+(1-\Omega) \lambda E_{\mathrm{X}}
$$

where

$$
\lambda E_{Q}=Q_{A}[s /(s+\gamma)] ;
$$

$\lambda E_{\mathrm{X}}=\rho C_{\mathrm{p}} \delta e / \gamma r_{\mathrm{s}}$;

$\Omega=1 /\left\{1+[\gamma /(s+\gamma)]\left(r_{\mathrm{s}} / r_{\mathrm{a}}\right)\right\}_{i}$

$Q_{A}$ is available energy at effective evaporating surface;

$\delta e$ is vapour pressure deficit;

$C_{\mathrm{p}}$ is the specific heat capacity of air at constant pressure;

$r_{\mathrm{a}}$ is aerodynamic resistance;

$r_{\mathrm{s}}$ is bulk canopy resistance;

$s$ is the slope of the curve of saturated vapour pressure versus temperature at mean air temperature;

$\gamma$ is the psychrometric constant;

$\lambda$ is the latent heat of vaporization of water;

$\rho$ is air density.

The term $\Omega \lambda E_{Q}$ is the rate of evaporation that would obtain if the heat budget of a surface were dominated by the diabatic (radiative) term. This condition tends to be satisfied when short well-watered vegetation is exposed to bright sunshine, humid air and a light wind. The complementary adiabatic term $(1-\Omega) \lambda E_{\mathrm{X}}$ is the rate of evaporation 'imposed' by the environment when the surface is 'fully coupled' to the prevailing weather. Values of the uncoupling coefficient $\Omega$ for the growing bracken canopy during 1984 are reproduced in Fig. 2. As the bracken canopy develops so the value of $\Omega$ for the canopy increases from nearly zero on Day 150 to around 0.4 on Day 210 , suggesting a progressive increase in the importance of the diabatic term and therefore the radiative input in driving the evaporative loss. The value of $\Omega$ for the combined canopy and moist soil surface is of course always high. The term $\lambda E_{Q}$ does not directly contain the bulk canopy resistance $r_{\mathrm{s}}$, and therefore if this term dominates the total evaporative loss, the loss will be largely independent of the bulk canopy resistance. The uncoupling term $\Omega$ increases for the growing bracken canopy because the value of the bulk canopy resistance $r_{\mathrm{s}}$ decreases more rapidly than the value of the aerodynamic resistance $r_{a}$ (Table 1).

Fig. 2. Noon values of the uncoupling coefficient $\Omega$ for (a) the growing bracken canopy during 1984, and estimated values during 1984 for (b) grass and (c) coniferous forest. See text for details of vegetation covers
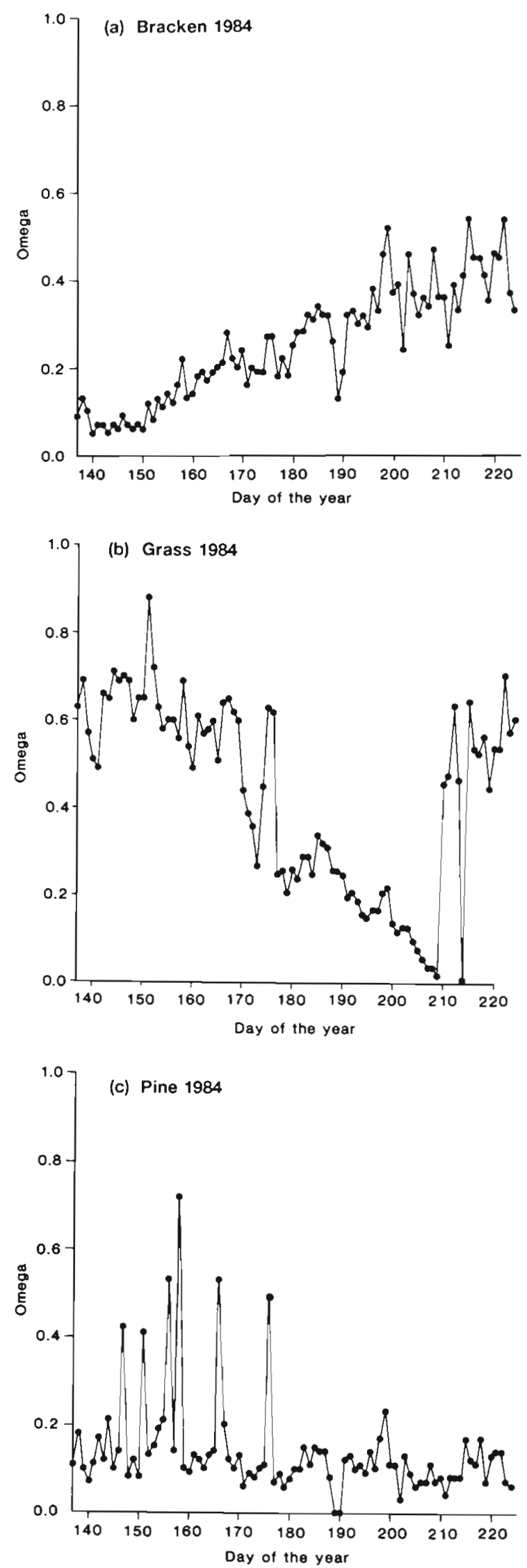
For comparison, estimated $\Omega$ values for hypothetical covers of moorland grass (height $0.15 \mathrm{~m}$, LAI 5, maximum available water content of soil $70 \mathrm{~mm}$ ) and coniferous forest (height $10 \mathrm{~m}$. LAI 6, maximum avilable water content of soil $175 \mathrm{~mm}$ ) are also shown in Fig. 2. The values are typical of those described by McNaughton \& Jarvis (1983) for the 2 vegetation types. The pine $\Omega$ values are around 0.1 and show little seasonal variation, since unlike bracken the canopy characteristics are constant over the period. In contrast the $\Omega$ values for grass are initially around 0.7 , the normal values for grass, but decrease sharply towards Day 210 as the bulk canopy resistance increases in response to severely limited soil moisture.

Fig. 3 illustrates the operation of the physical processes which underlie evaporative loss from bracken. In the stomatal conductance scheme used in this paper, variations in incoming shortwave radiation do not produce significant changes in stomatal conductance for incoming radiation values above ca $100 \mathrm{~W} \mathrm{~m} \mathrm{~m}^{-2}$. Similarly for relatively moist soils, stomatal conductance is not influenced by small changes in soil moisture. Therefore on a bright summer day, with nonlimiting soil moisture, stomatal conductance and bulk canopy resistance will respond strongly to changes in atmospheric specific humidity deficit. This is illustrated in Fig. 3 where the LAI is 2, temperature in the 20 to $25^{\circ} \mathrm{C}$ range, and soil moisture non-limiting. With aerodynamic resistance $r_{2}$ set to a typical value for bracken at this site of $20 \mathrm{~s} \mathrm{~m}^{-1}$, it is observed in Fig. 3 that the value of the adiabatic term $(1-\Omega) \lambda E_{\mathrm{X}}$ is small with humid atmospheres, increases to reach a maximum value with a specific humidity deficit of about $9 \mathrm{~g} \mathrm{~kg}^{-1}$ and then decreases with increasing atmospheric humidity deficit. This illustrates the interaction between the model stomatal resistance scheme and atmospheric humidity, and illustrates the very strong stomatal control on transpiration in dry atmospheres. Total transpiration losses for equilibrium (diabatic) evaporation values $\lambda E_{Q}$ of 100,200 and $300 \mathrm{~W} \mathrm{~m}^{-2}$ (corresponding approximately to net radiation values of 133,267 and $400 \mathrm{~W} \mathrm{~m}^{-2}$ respectively) are also shown. With $\lambda E_{Q}$ set to $100 \mathrm{~W} \mathrm{~m}^{-2}$, maximum transpiration occurs with a specific humidity deficit of around $9 \mathrm{~g} \mathrm{~kg}^{-1}$. As the value of $\lambda E_{Q}$ increases, maximum transpiration occurs at lower specific humidity deficits, with around $7 \mathrm{~g} \mathrm{~kg}^{-1}$ being reached with $\lambda E_{Q}$ set at $300 \mathrm{~W} \mathrm{~m}^{-2}$. For comparison, values are also shown in Fig. 3 with $r_{a}$ set to $50 \mathrm{~s} \mathrm{~m}^{-1}$, a value typical of short smooth vegetation. With $\lambda E_{Q}$ set at either 300 or $200 \mathrm{~W} \mathrm{~m}^{-2}$, the transpiration loss at all specific humidity deficits with $r_{\mathrm{a}}$ values of $50 \mathrm{~s} \mathrm{~m}^{-1} \mathrm{ex}-$ ceed those for $r_{\mathrm{a}}$ equal to $20 \mathrm{~s} \mathrm{~m}^{-1}$. For $\lambda E_{Q}$ values of $100 \mathrm{~W} \mathrm{~m}^{-2}$, the transpiration loss at $r_{\mathrm{a}}$ equal to $50 \mathrm{~s} \mathrm{~m}^{-1}$ exceeds that at $20 \mathrm{~s} \mathrm{~m}^{-1}$, except over the range of specific humidity deficits between 7 and $11 \mathrm{~g} \mathrm{~kg}^{-1}$ when the transpiration loss exceeds the value of $\lambda E_{Q}$. These results are in agreement with the findings of Dickinson (1980) and Rowntree (1988) in regard to the effect of turbulence on the partitioning between sensible and latent heat fluxes from dry canopies. The increased amount of turbulence produced by a rough dry canopy preferentially increases the flux of sensible heat with
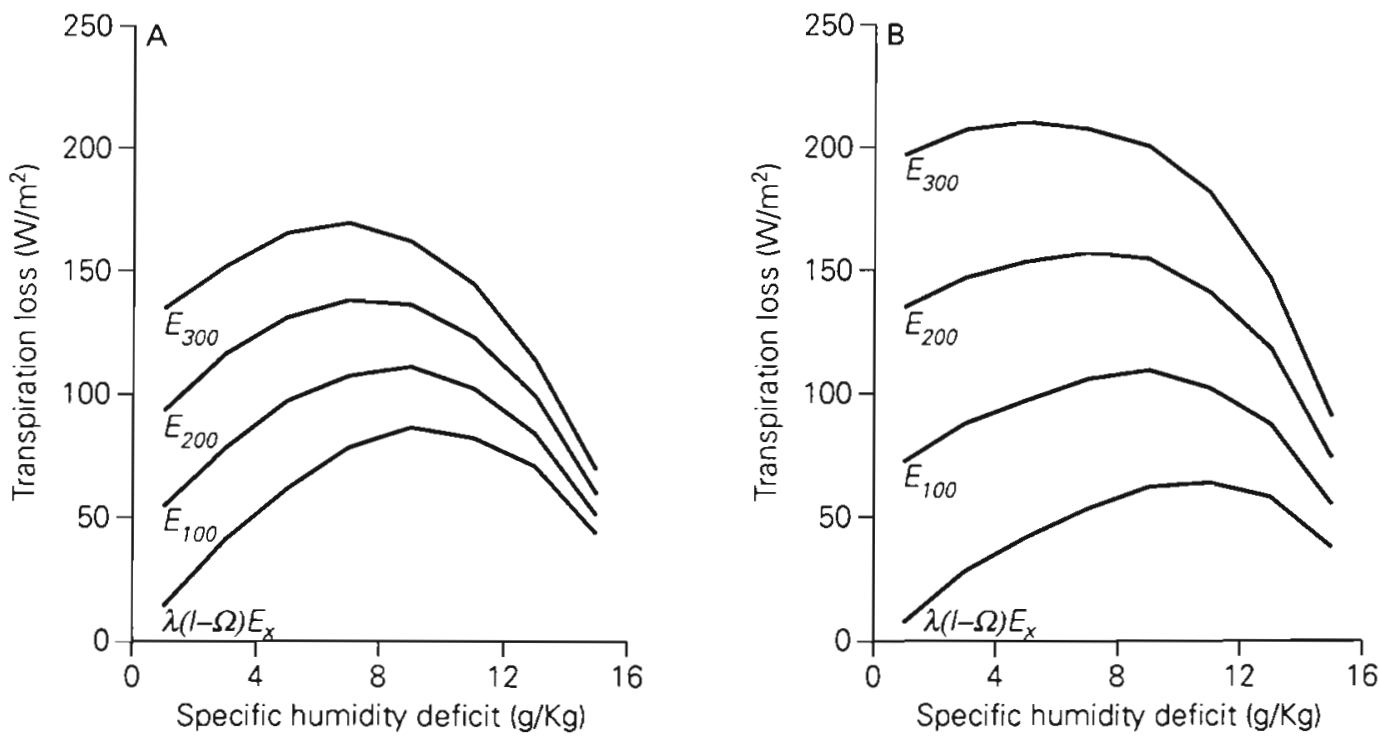

Fig. 3. Transpiration loss from a bracken canopy (LAI 2, bright sunlight with a moist soil) under various atmospheric humidity deficits. (A) Aerodynamic resistance of $20 \mathrm{~s} \mathrm{~m}^{-1}$; (B) aerodynamic resistance of $50 \mathrm{~s} \mathrm{~m}^{-1} E_{100}$, $E_{200}$, and $E_{300}$ are the total transpiration rates for $\lambda E_{Q}$ values of 100,200 , and $300 \mathrm{~W} \mathrm{~m}^{-2}$ respectively. $\lambda(1-\Omega) E_{\mathrm{X}}$ is the adiabatic component of the total transpiration rate. See text for further details 

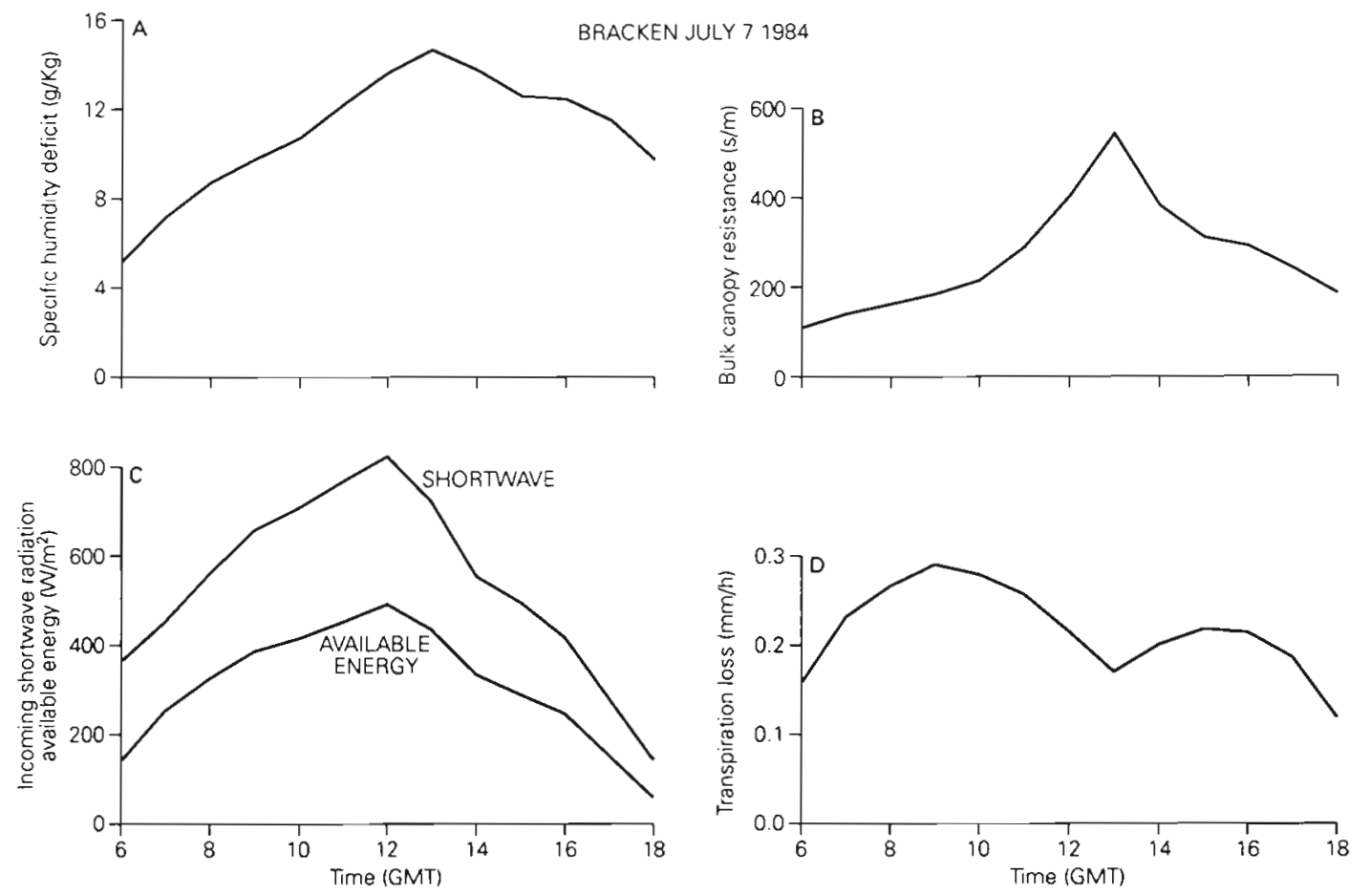

Fig. 4. Simulated transpiration loss from a bracken canopy (LAI 2.8, height $0.67 \mathrm{~m}$ ) for July 7, 1984. (A) Observed specific humidity deficits $\left(\mathrm{g} \mathrm{kg}^{-1}\right)$; (B) estimated bracken bulk canopy resistance $\left(\mathrm{s} \mathrm{m}^{-1}\right)$; (C) observed incoming short-wave radiation and available energy $\left(\mathrm{W} \mathrm{m}^{-2}\right)$; (D) estimated transpiration loss $\left(\mathrm{mm} \mathrm{h}^{-1}\right)$

moist air, and thus reducing vegetable roughness could increase evapotranspiration. In the case examined here, apart from the one exception, sensible heat flux increases with increasing roughness; it also tends to decrease at first, with increasing specific humidity deficit reaching a minimum value, and then increases markedly with further increases in humidity deficit.

Atmospheric humidity deficit on fine dry days shows very marked diurnal variations, with low values at night and maximum values during the afternoon. Because of the strong control of bulk canopy resistance by atmospheric humidity deficit, both bulk canopy resistance and transpiration loss also show marked diurnal variations. This is illustrated for a sunny dry day in Fig. 4, where it is seen that as the specific humidity deficit increases during the morning, so also does the bulk canopy resistance. This in turn is reflected by a fall in transpiration rates across the midday period, even though available energy (net radiation - soil heat flux) is at a maximum. Within the model parameterization, atmospheric specific humidity deficit does not directly influence soil surface resistance. Therefore, as illustrated in Fig. 5, evaporation from a moist bare soil surface is a function of available energy, atmospheric specific humidity deficit and bare soil aerodynamic resistance, in this case producing a maximum evaporation rate in the afternoon.

\section{(6) SENSITIVITY STUDY OF CHANGES IN BULK CANOPY RESISTANCE}

The discussion in the previous section suggests that the scope for variations in bulk canopy resistance to directly influence transpiration loss may be limited. For short crops in well-watered soils where the evaporative loss approximates to $\lambda E_{Q}$ it is likely to be very small. For vegetation canopies such as bracken with low values of the uncoupling coefficient $\Omega$ it varies with the meteorological conditions, from very small to a significant but limited influence. It should be noted that variations in bulk canopy resistance also feed back into effective canopy temperatures which in turn influence canopy long-wave radiation loss and therefore net radiation and available energy values. For example, if the soil under a grass pasture becomes dry this will stress the grass, causing its bulk canopy resistance to increase. In turn this will cause the value of the uncoupling coefficient $\Omega$ to decrease, as shown in Fig. 2, making the adiabatic component of the evaporation relatively more important, but also it causes the canopy and near-surface atmospheric temperature to rise, resulting in a decrease in the available energy at the canopy surfaces to drive the diabatic component of the evaporative loss $\lambda E_{Q}$. The net result of these changes is a decrease in the 

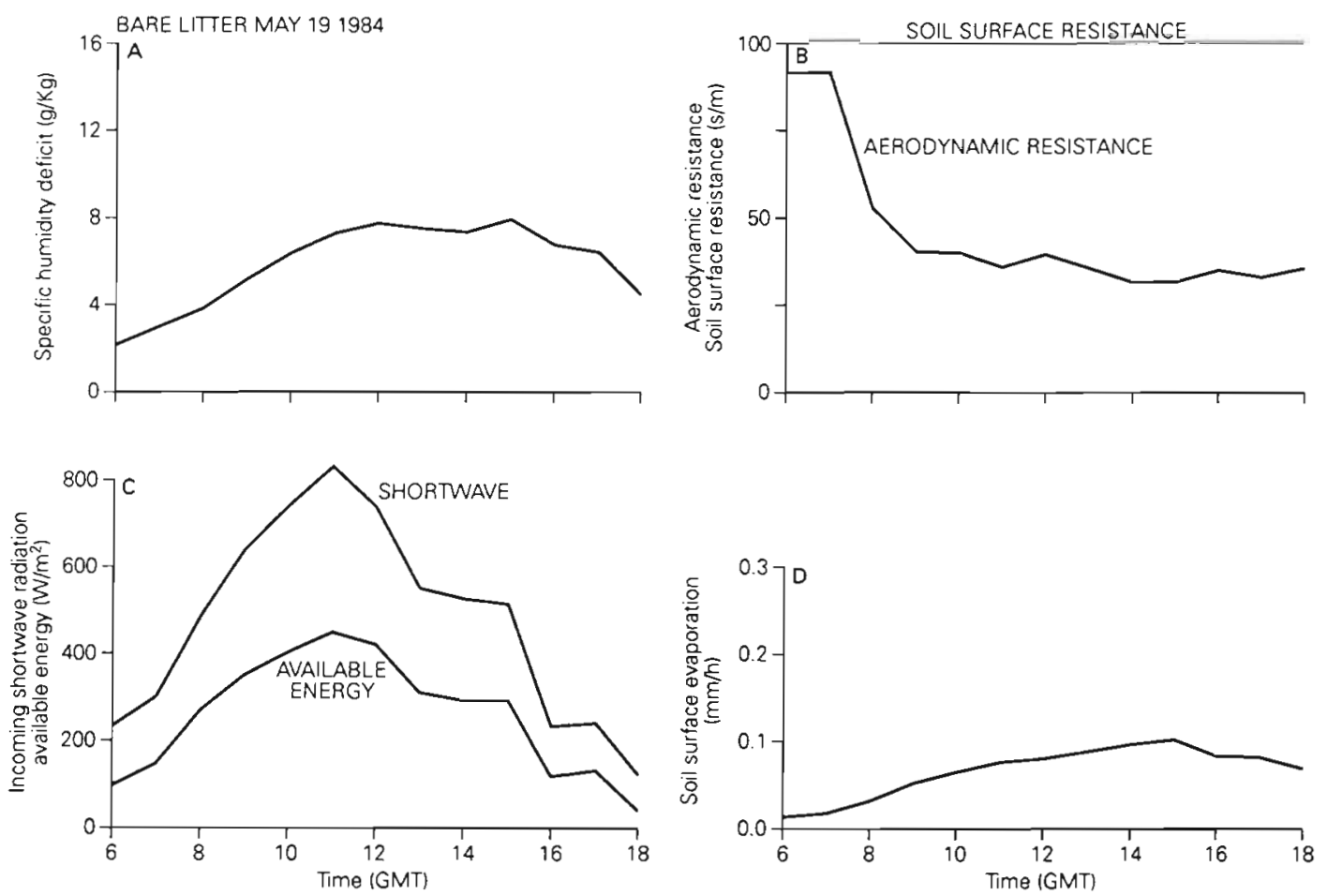

Fig. 5. Simulated evaporation from a bare litter-covered surface for May 19, 1984. (A) Observed specific humidity deficit (g kg ${ }^{-1}$ ); (B) estimated soil surface resistance and aerodynamic resistance ( $\left.\mathrm{sm}^{-1}\right)$; (C) observed incoming short-wave radiation and available energy $\left(\mathrm{W} \mathrm{m}^{-2}\right)$; (D) estimated soil surface evaporation $\left(\mathrm{mm} \mathrm{h}^{-1}\right)$

transpiration loss from the pasture. If the canopy temperature increases too much it will eventually kill the grass. The model used to estimate interception loss also yields estimates of transpiration and soil surface evaporation bulked together, as well as effective surface temperature. Estimates were made using the model for Days 200 to 204, when the canopy cover was complete, of effective canopy temperatures for the cases with bulk canopy resistance increased or decreased by $20 \%$. Values were obtained of daily averages across the period 09:00 to 18:00 h (GMT) when active transpiration was occurring. For the $5 \mathrm{~d}$ period with canopy resistance decreased by $20 \%$ the mean canopy temperature was $19.9^{\circ} \mathrm{C}$; for an increase of $20 \%$ the canopy temperature became $20.3^{\circ} \mathrm{C}$. The estimated effective canopy temperature differences are small, around $0.5^{\circ} \mathrm{C}$, and are equivalent to a change in long-wave emission of about $3 \mathrm{~W}$ $\mathrm{m}^{-2}$. In this case changes in canopy temperature are not strongly influencing evaporative loss, but the nature of the net radiation input to the model may be constraining the result.

The results of the sensitivity study using bulk canopy resistances increased or decreased by $20 \%(+20 \%$ and $-20 \%$ cases) from the standard control model are shown in Figs. 6 to 8 and Tables 4 to 6 . As explained in the introduction, variations in bulk canopy resistance are kept small so as not to change the above-canopy meteorological conditions, and the $\pm 20 \%$ variation was chosen for this reason. Changing the bulk canopy resistance mainly changes the transpiration loss, though there is a small effect on soil surface evaporation induced by changes in soil moisture. As would be expected from the discussion in the previous section, the percentage change in canopy transpiration rate is always less than the corresponding percentage change in canopy resistance. Even more significant are the variations of total evapotranspiration shown in Table 6 . For LAI values below 1 (before Day 165), i.e. sparse vegetation covers, changing the bulk canopy resistance by $20 \%$ does not significantly change the absolute evapotranspiration loss. This is because the evapotranspiration is small, and up to half of the total evapotranspiration loss is from sources other than canopy transpiration (e.g. soil surface evaporation and interception loss) as shown in Tables 4 \& 5 . For LAI values above 1 (after Day 165), the absolute changes in evapotranspiration are significant but the percentage variations are still small. This is clearly seen in the simulations of soil moisture deficit shown in Fig. 8. The simulated soil moisture deficits only diverge after Day 165; the divergence reaches a maximum just after Day 190 before the soil moisture in the $-20 \%$ case becomes limiting. 
Fig. 6. Simulated transpiration loss $\left(\mathrm{mm} \mathrm{d}^{-1}\right)$ from the bracken canopy during 1984. RSC $+20 \%$, RSC - Norm., and RSC $-20 \%$ refer to the $+20 \%$ canopy resistance, the standard control and the $-20 \%$ resistance cases respectively

Figs. $6 \& 7$ show, for the control and the 2 perturbed cases $(+20 \%$ and $-20 \%)$, transpiration alone and transpiration plus soil surface evaporation. The 2 curves are similar but the second is dominated by soil evaporation in the early stages up to about Day 160. As would be expected the curve for the highest bulk canopy resistance has the lowest evaporative loss. The greatest soil moisture deficits (Fig. 8) occur in the $-20 \%$ case, which also mostly has the highest transpiration rates from Days 170 to 200. Around Day 200 the soil moisture in the $-20 \%$ case becomes severely limited and markedly restricts the transpiration loss. Soon afterwards the same applies in the control case, and the soil moisture deficits in Fig. 8 become equal in both cases. In this case reducing the bulk canopy resistance by $20 \%$ short-

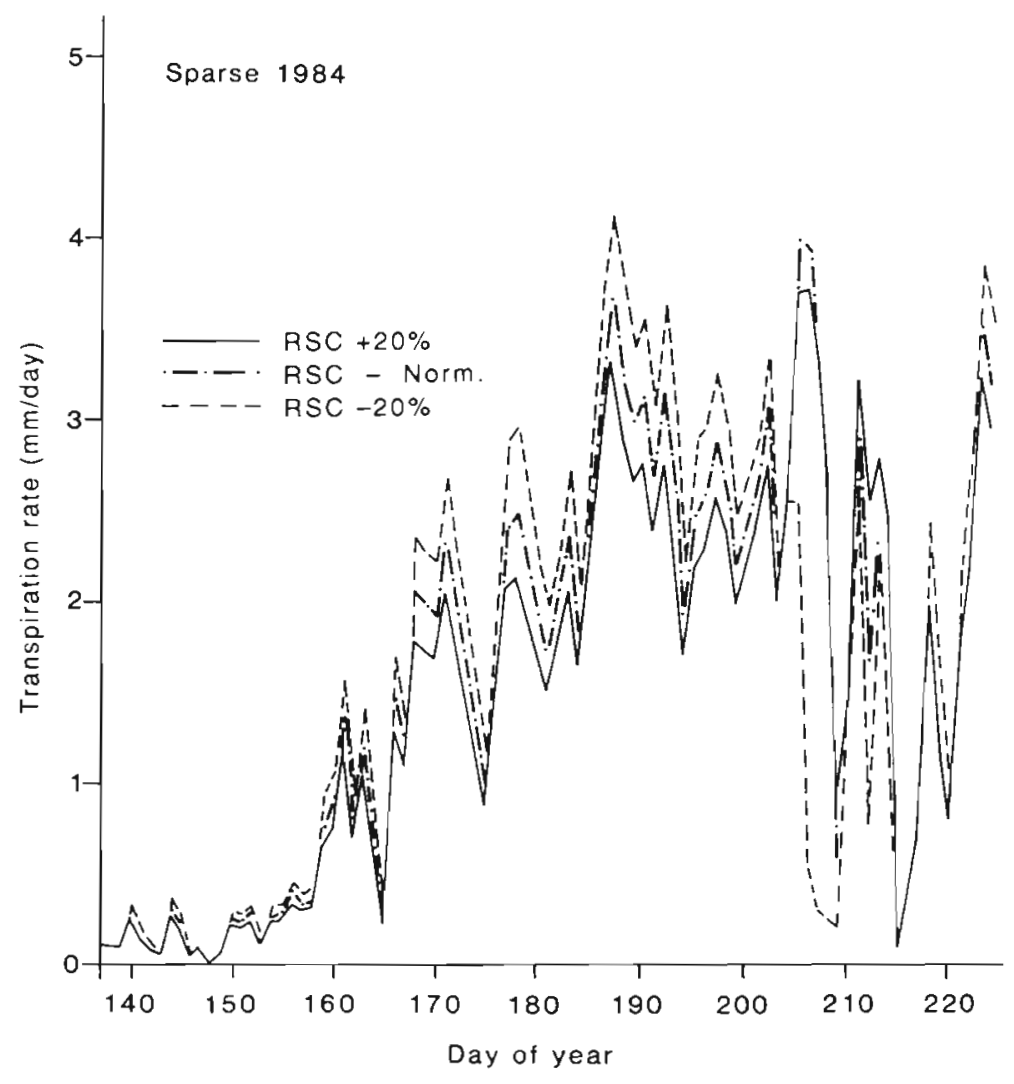

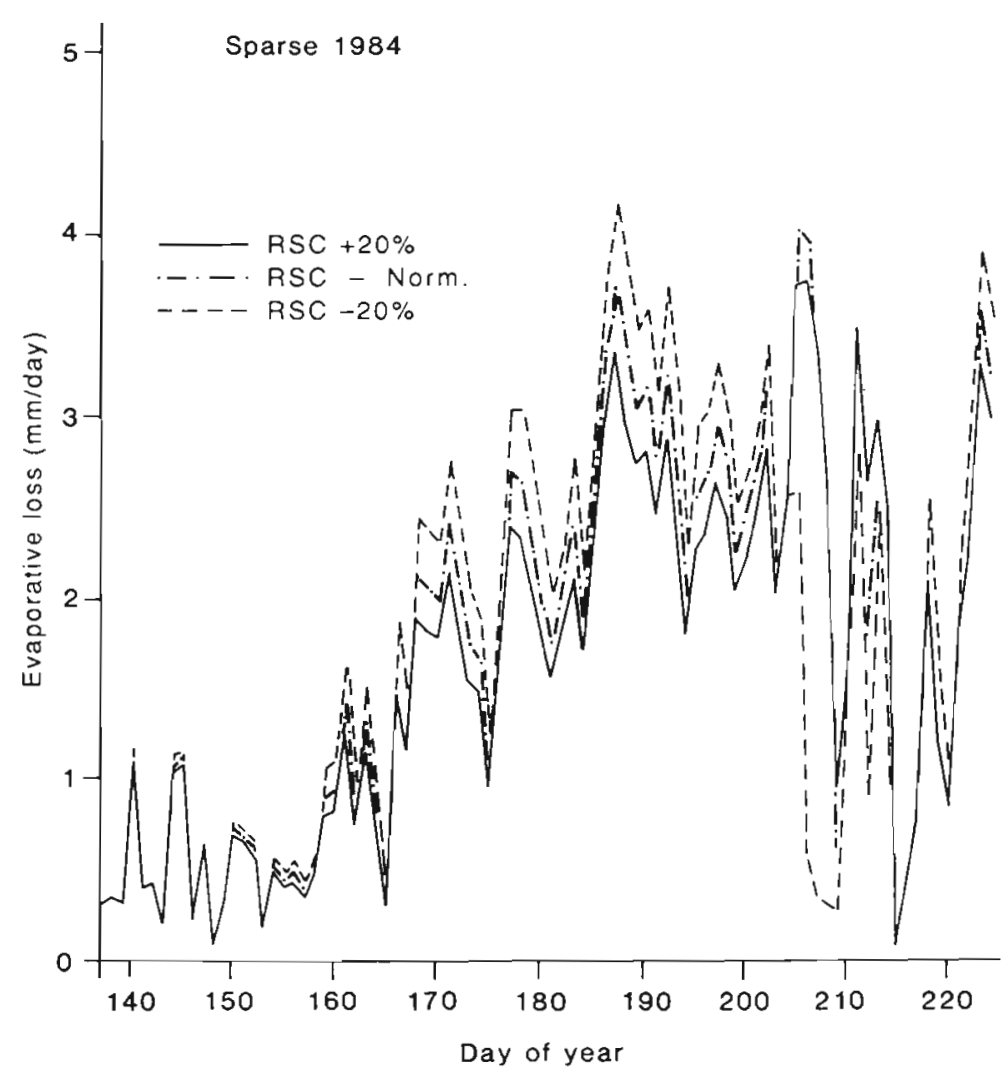

ens the time to effective soil moisture exhaustion by about $5 \mathrm{~d}$ or around $10 \%$ As noted above the variations in soil moisture due to canopy resistance changes are most marked at depths away from the influence of soil surface evaporation.

\section{(7) SENSITIVITY STUDY OF CHANGES IN LAI AND VEGETATION HEIGHT}

Increases in atmospheric $\mathrm{CO}_{2}$ content may directly improve vegetation growth, and also indirectly through increased temperature and therefore an earlier start to the growing season (Idso 1989). Comment was made earlier that bracken transpiration rates become nearly constant when LAI values reach about 2 , probably because the canopy is intercepting the maximum possible amount of sunlight and because of limitations in the rate

Fig. 7. Simulated transpiration plus soil surface evaporation $\left(\mathrm{mm} \mathrm{d}^{-1}\right)$ for the bracken stand during 1984. Key as in Fig. 6 


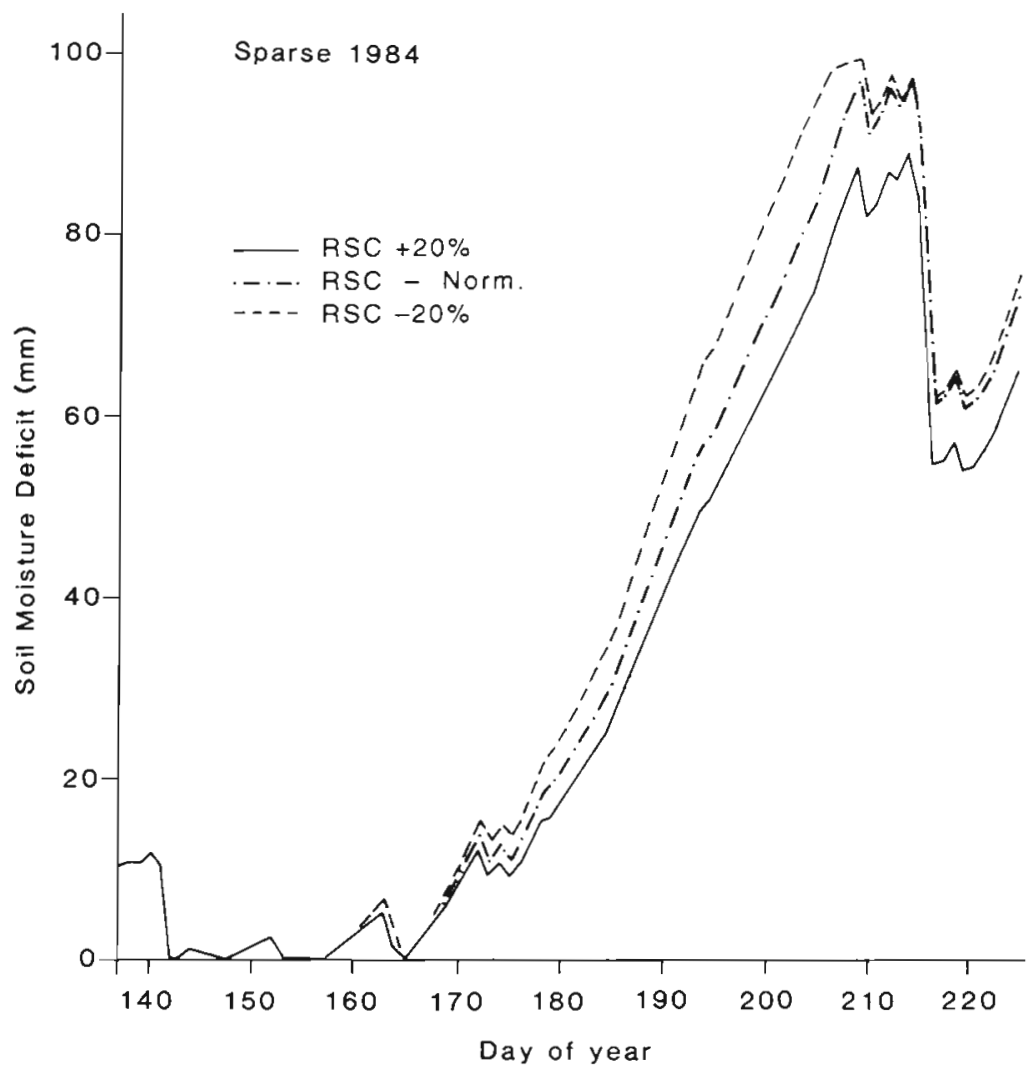

Fig. 8. Simulated soil moisture deficits under the bracken canopy during 1984. Key as in Fig. 6

bations effectively cancel each other. Therefore the curves in Figs. 6 to 8 for the $-20 \%$ resistance case can also be taken to refer to the case of LAI increased by $20 \%$. Examination of the individual evaporative components highlights differences between the cases of canopy resistance reduced by $20 \%$ (Table 4 ) and LAI increased by $20 \%$ (Table 7 ). In each decade, increasing the LAI slightly increases the interception loss because of the enhanced canopy water storage. Soil surface evaporative loss in the increased LAl case is slightly reduced between Days 150 and 169 and then very slightly increases for the rest of the period. This probably reflects the very strong control of the slightly increased within-canopy aerodynamic resistance acting in the early period on a moist soil and in the later stages on a dry soil with a high surface resistance. The physical processes involved are discussed in Section 5.

Changes in bracken canopy height may influence the aerodynamic resistance and this will affect the evaporative loss. In Table 8 the growth scheme describing the development of bracken height is varied by the percentage amounts shown, that is, the control height on the given day is in turn multiplied by 10,50 , 100 and $200 \%$. The variations in transpiration loss with increasing canopy height are small, agreeing with the comments of Rowntree (1988) that canopy height does not strongly influence total evapotranspiration loss from dry canopies. Up to Day 190 there is a slight fall in transpiration loss with increasing height

Table 5. Evaporative loss for bulk surface resistance of bracken canopy increased by $20 \%, 1984$. Percentage of control given in parentheses

\begin{tabular}{|lrccc|}
\hline Days & Transpiration & \multicolumn{2}{c}{$\begin{array}{c}\text { Soil } \\
\text { evaporation } \\
(\mathrm{mm})\end{array}$} & $\begin{array}{c}\text { Interception } \\
\text { loss } \\
(\mathrm{mm})\end{array}$ \\
\hline $150-159$ & $2.85(85.5)$ & 2.07 & 0.82 \\
$160-169$ & $10.40(87.0)$ & 0.87 & 1.50 \\
$170-179$ & $16.38(86.1)$ & 1.63 & 1.52 \\
$180-189$ & $22.75(89.0)$ & 0.50 & 0.41 \\
$190-199$ & $23.34(89.2)$ & 0.60 & 1.40 \\
$200-209$ & $25.99(96.7)$ & 0.31 & 1.85 \\
Total & 101.71 & 5.98 & 7.5 \\
\hline
\end{tabular}


Table 6. Evapotranspiration for bracken control and bulk canopy resistance modified cases. Values in $\mathrm{mm}$; percentages of control given in parentheses

\begin{tabular}{|lrrrrr|}
\hline Days & $\begin{array}{c}\text { Canopy } \\
\text { resistance } \\
\text { decreased } \\
\text { by 20\% }\end{array}$ & Control & \multicolumn{2}{c|}{$\begin{array}{c}\text { Canopy } \\
\text { resistance } \\
\text { increased } \\
\text { by } 20 \%\end{array}$} \\
\hline $150-159$ & $6.78(109.0)$ & 6.22 & 5.74 & $(92.2)$ \\
$160-169$ & $16.03(111.9)$ & 14.32 & 12.77 & $(89.2)$ \\
$170-179$ & $24.97(113.4)$ & 22.01 & 19.53 & $(88.7)$ \\
$180-189$ & $29.73(112.6)$ & 26.40 & 23.66 & $(89.6)$ \\
$190-199$ & $32.06(113.9)$ & 28.14 & 25.34 & $(90.0)$ \\
$200-209$ & $19.68(67.8)$ & 29.03 & 28.15 & $(97.0)$ \\
Total & $129.25(102.5)$ & 126.12 & 115.19 & $(91.3)$ \\
\hline
\end{tabular}

Table 7. Evaporative loss on increasing standard LAI of bracken canopy by $20 \%$. Values in $\mathrm{mm}$

\begin{tabular}{|lrrrr|}
\hline Days & $\begin{array}{c}\text { Trans- } \\
\text { piration }\end{array}$ & $\begin{array}{c}\text { Soil } \\
\text { evapo- } \\
\text { ration }\end{array}$ & $\begin{array}{c}\text { Inter- } \\
\text { ception } \\
\text { loss }\end{array}$ & $\begin{array}{r}\text { Total } \\
\text { evapo- } \\
\text { ration }\end{array}$ \\
\hline $150-159$ & 3.95 & 1.67 & 0.94 & 6.56 \\
$160-169$ & 13.72 & 0.72 & 1.62 & 16.06 \\
$170-179$ & 21.97 & 1.25 & 1.67 & 24.89 \\
$180-189$ & 28.56 & 0.48 & 0.51 & 29.55 \\
$190-199$ & 29.57 & 0.62 & 1.66 & 31.85 \\
$200-209$ & 17.77 & 0.48 & 1.88 & 20.13 \\
Total & 115.54 & 5.22 & 8.28 & 129.04 \\
\hline
\end{tabular}

(Table 8); after Day 190 the situation is less clear. This is consistent with the discussion of Fig. 3. With very sparse vegetation covers and moist soil surfaces up to Day 159, soil surface evaporative loss decreases with increasing vegetation height and therefore increasing aerodynamic resistance; after Day 159 the gradient reverses and soil surface evaporative loss increases with increasing vegetation height. In this case, with very sparse covers, the canopy stomatal control of total evaporative loss with similar LAI values is greater with tall canopies than short. This again partly reflects the interaction between soil surface resistance and within-canopy aerodynamic resistance observed with the LAl study and also discussed in Section 5. With a wet soil surface (surface resistance $100 \mathrm{~s} \mathrm{~m}^{-1}$ ), soil evaporative loss increases with decreasing withincanopy aerodynamic resistance (i.e. with lower canopies). In the dry soil case (high soil surface resistance), the evaporative loss increases with increasing withincanopy aerodynamic resistance (i.e. with higher canopies). Estimated rainfall throughfall (not shown) decreases with increasing canopy height because of the strong association between canopy roughness and interception loss. Computed effective surface temperatures at 14:00 h (GMT) are presented in Table 9. These show a consistent decrease with increasing height, suggesting again a greater sensible heat loss from the aerodynamically rougher canopies with a parallel decrease in the long-wave radiation loss.

\section{(8) CONCLUSIONS}

The object of this paper was to describe 2 numerical experiments which determine the sensitivity of evaporation loss and soil moisture to changes in canopy characteristics. The first numerical experiment described the changes in evaporative partitioning as the canopy develops from a bare surface to a full cover. The second described the influence of small changes in the characteristics of the growing canopy on evaporative partitioning. In the first experiment it was demonstrated that soil surface evaporation from moist soils is

Table 8. Evaporative loss for height of bracken canopy increased or decreased to various percentages. Mean 10-day canopy heights $(\mathrm{m})$ for the standard $(100 \%)$ case are shown in parentheses

\begin{tabular}{|c|c|c|c|c|c|c|c|c|}
\hline \multirow[t]{2}{*}{ Days } & \multicolumn{4}{|c|}{ Transpiration (mm) } & \multicolumn{4}{|c|}{ Soil evaporation (mm) } \\
\hline & $10 \%$ & $50 \%$ & $100 \%$ & $200 \%$ & $10 \%$ & $50 \%$ & $100 \%$ & $200 \%$ \\
\hline $150-159$ & 3.74 & 3.44 & $\begin{array}{c}3.33 \\
(0.114)\end{array}$ & 3.15 & 2.99 & 2.34 & 2.07 & 1.81 \\
\hline $160-169$ & 13.69 & 13.28 & $\begin{array}{c}11.96 \\
(0.272)\end{array}$ & 11.17 & 0.52 & 0.71 & 0.86 & 1.03 \\
\hline $170-179$ & 20.81 & 19.47 & $\begin{array}{c}19.02 \\
(0.431)\end{array}$ & 18.23 & 0.78 & 1.18 & 1.47 & 1.93 \\
\hline $180-189$ & 26.43 & 25.77 & $\begin{array}{c}25.56 \\
(0.590)\end{array}$ & 25.21 & 0.27 & 0.30 & 0.43 & 0.60 \\
\hline $190-199$ & 25.52 & 25.93 & $\begin{array}{c}26.16 \\
(0.733)\end{array}$ & 26.93 & 0.36 & 0.47 & 0.58 & 0.84 \\
\hline $200-209$ & 26.53 & 26.83 & $\begin{array}{c}26.87 \\
(0.908)\end{array}$ & 25.59 & 0.24 & 0.26 & 0.31 & 0.55 \\
\hline
\end{tabular}


Table 9. Effective surface temperatures $\left({ }^{\circ} \mathrm{C}\right)$ at 14:00 h GMI for height of bracken canopy increased or decreased to various percentages. na: not available; mean 10-day canopy heights $(\mathrm{m})$ for the standard $(100 \%)$ case are shown in parentheses

\begin{tabular}{|c|c|c|c|c|c|}
\hline Days & $10 \%$ & $50 \%$ & $100 \%$ & $200 \%$ & $\begin{array}{c}\text { Air } \\
\text { temp. } \\
\text { at } 2 \mathrm{~m}\end{array}$ \\
\hline $150-159$ & 20.2 & 18.1 & $\begin{array}{c}17.3 \\
(0.114)\end{array}$ & 16.5 & 14.2 \\
\hline $160-169$ & 23.7 & 21.3 & $\begin{array}{c}20.4 \\
(0.272)\end{array}$ & 19.6 & 18.1 \\
\hline $170-179$ & 22.7 & 20.6 & $\begin{array}{c}19.7 \\
(0.431)\end{array}$ & 19.0 & 18.2 \\
\hline $180-189$ & 22.8 & 20.6 & $\begin{array}{c}19.7 \\
(0.590)\end{array}$ & 18.8 & 18.1 \\
\hline $190-199$ & 23.5 & 21.2 & $\begin{array}{c}20.5 \\
(0.733)\end{array}$ & 19.8 & 19.6 \\
\hline $200-209$ & na & na & $\begin{array}{c}21.3 \\
(0.908)\end{array}$ & 20.4 & 20.2 \\
\hline
\end{tabular}

an important component of the total evaporative loss in very sparse canopies (LAI below 0.5). That is, with LAI values below about 0.5 , and moist soils, canopy stomatal controls are not strongly influencing total evaporative loss. In contrast, there is a tendency for 10-day average transpiration to become constant with increasing LAI for LAI values above ca 2. It was also demonstrated that soil surface evaporation dries the top $20 \mathrm{~cm}$ of the soil, while transpiration from the bracken cover reduces soil moisture well below this depth. The main conclusion of the second experiment is that the percentage change in canopy transpiration loss is always considerably less than the percentage change in the particular canopy characteristic. This is particularly so for changes in bulk canopy resistance. The reasons for this were explored in terms of the adiabatic and diabatic components of the evaporative loss. Inspection of Table 3 shows that there were considerable variations in the evaporative loss between years, resulting from interannual variations in both rainfall and net radiation. These were at least as large as the changes in evaporative loss resulting from small changes in canopy characteristics. This suggests that interannual variations in weather may swamp small changes in canopy characteristics resulting either from longterm climatic changes or from errors in field parameterizations

Comment has been made about the very strong control of atmospheric humidity deficit on bulk canopy resistance and therefore transpiration loss. This is further explored in Table 10, where its influence on transpiration loss is examined by varying the measured atmospheric specific humidity deficits by various percentage
Table 10. Transpiration loss (mm) for observed atmospheric humidity deficits increased or decreased to various percent. ages

\begin{tabular}{|lrrrrr|}
\hline Days & $140 \%$ & $120 \%$ & $100 \%$ & $80 \%$ & $60 \%$ \\
\hline $150-159$ & 3.00 & 3.15 & 3.33 & 3.44 & 3.58 \\
$160-169$ & 10.40 & 11.13 & 11.96 & 12.47 & 13.09 \\
$170-179$ & 15.64 & 17.29 & 19.02 & 20.31 & 21.67 \\
$180-189$ & 20.59 & 22.94 & 25.56 & 27.66 & 29.56 \\
$190-199$ & 22.20 & 24.21 & 26.16 & 28.12 & 29.75 \\
$200-209$ & 24.58 & 26.53 & 26.87 & 22.50 & 17.74 \\
Total & 96.41 & 105.25 & 112.90 & 114.50 & 115.39 \\
\hline
\end{tabular}

amounts. Except where limiting soil moisture intervenes, reducing the humidity deficit increases the transpiration loss. Reducing the humidity deficit to $60 \%$ of the measured values has roughly the same effect on transpiration loss as reducing the bulk canopy resistance by $20 \%$. Similarly, increasing the humidity deficit to about $130 \%$ of its measured values is equivalent to increasing the bulk canopy resistance by $20 \%$. This stresses the need to measure atmospheric humidity deficits correctly when determining transpiration rates

The conclusions of this paper must be viewed with some caution because they arise from the application of one particular numerical model to one particular growing vegetation cover. Nevertheless the stomatal response to environmental conditions of bracken is typical of many taller plants. Short grasses show a different response. The conclusions of this paper are therefore likely to be of wider application to areas covered by a variety of growing sparse vegetation covers.

\section{LITERATURE CITED}

Carlson, T N., Perry, E. M., Schmugge, T J. (1990). Remote estimation of soil moisture availability and fractional vegetation cover for agricultural fields. Agric. For. Meteorol. 52: $45-69$

Dickinson, R. E. (1980). Effects of tropical deforestation on climate. In: Blowing in the wind: deforestation and longrange implications. Studies in Third World Societies, No. 14. College of William and Mary, Dept of Anthropology, Williamsburg, VA, p. 411-441

Idso (1989). Carbon dioxide and global change: earth in transition. IBR Press, Tempe, AZ

Institute of Hydrology (1981). User's handbook for the Institute of Hydrology neutron probe system. Report 79. Institute of Hydrology, Wallingford

Kustas, W. P. (1990). Estimates of evapotranspiration with a one-layer and 2-layer model of heat-transfer over partial canopy cover. J. appl. Meteorol. 29: 704-715

Lafleur, P. M. Rouse, W. R. (1990). Application of an energy combination model for evaporation from sparse canopies Agric. For. Meteorol. 49: 135-153 
Lockwood, J. G. (1990). The influence of temperature variations on interception loss and water storage in vegetation canopies. Water Resour. Res. 26: 941-943

Lockwood, J. G. (1992). The sensitivity of the water balance of a wet multilayer model pine canopy to variations in meteorological input. Clim. Change 20: 23-56

Lockwood, J. G., Jones, C. A., Smith, R. T (1989). The estimation of soil moisture deficits using meteorological models at an upland moorland site in Northern England. Agric. For. Meteorol. 46: 41-63

McNaughton, K. G., Jarvis, P. G. (1983). Predicting effects of vegetation changes on transpiration and evaporation. In: Kozlowski, T T. (ed.) Water deficits and plant growth, Vol. 7. Academic Press, Orlando, p. 1-47

Monteith, J. L. (1986). How do crops manipulate water supply and demand? Phil. Trans. R. Soc. Lond. (Ser. A) 326: $245-259$

Monteith, J. L., Unsworth, M. H. (1990). Principles of environmental physics. Edward Arnold, London

Pitman. J. I. (1989). Rainfall interception by bracken in open habitats - relations between leaf area, canopy storage and drainage rate. J. Hydrol. 105: 317-334

Roberts, J., Wallace, J. S., Pitman, R. M. (1984). Factors affecting stomatal conductance of bracken below a forest

\section{Editor: G. Esser}

canopy. J. appl. Ecol. 21. 643-655

Rowntree, P. R. (1988). Review of general circulation models as a basis for predicting the effects of vegetation change on climate. In: Reynolds, E. R. C., Thompson, F. B. (eds.) Forests, climate and hydrology: regional impacts. The United Nations University, Tokyo, p. 162-196

Rutter, A. J., Kershaw, K. A., Robins, P. C., Morton, A. J. (1971). A predictive model of rainfall interception in forests. 1. Derivation of the model from observations in a plantation of Corsican Pine. Agric. Meteorol. 9: 367-384

Shuttleworth, W. J., Wallace, J. S. (1985). Evaporation from sparse crops - an energy combination theory. Q. J R Meteorol. Soc. 111:839-855

Strangeways, I. C., Smith, S. W. (1985). Development and use of automatic weather stations. Weather 40: 277-285

Thompson, N., Barrie, I. A., Ayles, M. (1981). The Meteorological Office rainfall and evaporation calculation system: MORECS (July 1981). Hydrological Memorandum 45. Meteorological Office, Bracknell, UK

Wallace, J. S., Roberts, J. M., Sivakumar, M. V. K. (1990). The estimation of transpiration from sparse dryland millet using stomatal conductance and vegetation area indices Agric. For. Meteorol. 51: 35-49

Manuscript first received: December 9, 1991 Revised version accepted: June 19, 1992 